\title{
Epistemology of testimony and values in science
}

\author{
Tihamér Margitay ${ }^{1}$ (D)
}

Received: 30 May 2019 / Accepted: 27 July 2020 / Published online: 1 September 2020

(c) The Author(s) 2020

\begin{abstract}
The paper has two interconnected objectives. It argues that the intrinsic epistemic value of testimonies (i.e., serving as evidence for what is asserted) can be reduced to their moral and social values, that is, to their competent, conscientious, and honest performance. Consequently, competence, conscientiousness, and honesty are intrinsic epistemic values in science. The second objective is to offer an answer to the questions why and under what conditions a hearer can rationally accept a testimony in science. The values and subsequent norms of testimony are espoused and strictly enforced by the scientific community. The norms of testimony ensure that rule-following scientists testify competently, conscientiously, and honestly. Due to value reduction, such testimonies also manifest their intrinsic epistemic value, that is, they serve as evidence for their content. So, if the norms of testimony are followed, then it is epistemically rational to adopt also the norm of the acceptance of testimonies. When the hearer accepts a testimony (unless he has counterevidence), he simply-and usually blindly-complies with this norm. Yet, he is epistemically rational because the norm he follows is epistemically rational, as well.
\end{abstract}

Keywords Values in science $\cdot$ Epistemic values $\cdot$ Epistemology of testimony $\cdot$ Social epistemology

\section{Introduction}

While many argue that moral and social values play a significant role in scientific knowledge, the character of these values and their epistemic significance require further clarifications. The received view is that reasoning on the acceptance of a scientific statement should rest exclusively on its epistemic values that are indicative of its truth. (Douglas 2009, 2016) This view is to guard against wishful thinking and secure the epistemic soundness of science. If other values were allowed to be used as a reason

Tihamér Margitay

margitay@gti.elte.hu

1 Institute of Business Economics, Eötvös Loránd University, Rákóczi Street 7, Budapest 1088, Hungary 
directly for or against the acceptance of a scientific claim, then this would ruin the rational empirical character of science. (Douglas 2016). While accepting the importance of epistemic values in science, I shall argue that general moral and social values ${ }^{1}$ also constitute epistemic values concerning testimonies. Consequently, they legitimately have a role to play in the decision about the acceptance of scientific statements (beliefs, claims, hypotheses, theories, etc.) that are based on testimonies.

Instead of a table of contents, let me present the skeleton of my arguments. The first part concerns the values of testimony and their role in science. The second part, in turn, discusses the epistemic rationality of the acceptance of testimonies.

Part one: Testimony is essential in science and cannot be reduced to other sources of justification. A testimony can manifest an epistemic value by being evidence for its content. However, I argue that this epistemic value of testimony can be reduced to the combined value of its competent, conscientious, and honest performance. Therefore, competence, conscientiousness, and honesty are also epistemic values. Thus, some moral and social values are epistemic values and have a role to play in the acceptance of scientific beliefs. By this value reduction, the epistemic value of testimony is grounded on and derived from its moral and social values.

Part two: Due to value reduction, competence, conscientiousness and honesty have a double-epistemic and social-function, opening the way to a group-level explanation of the epistemology of testimony. These values and their ensuing norms are necessary for cooperation, in general, and epistemic cooperation, in particular. That is why they are carefully observed and strictly enforced by the community. By enforcing competence, conscientiousness, and honesty in the performance of testimony, the scientific community also enforces the reliability of testimony. In a rule-following scientific community, a testimony is indeed a reason for the acceptance of its content. It is then epistemically rational for a scientific community to maintain also the norm of acceptance: take testimony as a reason for the acceptance of its content by default and challenge it only if you have good reasons to do so. In a rule-following community, it is an epistemically rational norm based on the intrinsic epistemic value of testimony. Indeed, scientific communities follow and enforce the norm of acceptance. By default, members of a scientific community simply_or rather, blindly_follow the rule of acceptance taking testimonies as evidence, and accepting the content of testimonies by virtue of this evidence. However, this acceptance is still epistemically rational because the norm governing it is epistemically rational, as well.

\section{Values in science}

For the sake of simplicity, let us proceed from the assumption that truth is the most fundamental epistemic value. Steel (2010) classified values in the following way (see also Rolin 2015).

\footnotetext{
1 I use the term moral and social value in a general sense to refer to values that are prima facie non-epistemic values, which are usually not considered as epistemic and, consequently, are denied any role in the decision about acceptance. It would not be a happy choice to use the term non-epistemic moral and social values to refer to them because I shall argue that some of them are, in fact, epistemic values concerning testimonies.
} 
Epistemic values promote the attainment of truth (Steel 2010, p. 15, p. 18). Within this cluster,

- "a value is intrinsically epistemic if exemplifying that value either constitutes an attainment of truth or is a necessary condition for a statement to be true" (Steel 2010, p. 18). (E.g., evidence, justification, empirical accuracy, internal consistency, etc.).

- extrinsic (instrumental) epistemic values "promote the search for truth without themselves being indicators or requirements of truth" (Steel 2010, p. 18). (e.g., simplicity, diversity, open-mindedness, proper research funding, etc.). They help us to attain intrinsic values.

Values falling outside of these categories are non-epistemic values.

Intrinsic epistemic values should directly influence scientists' decisions about the acceptance of scientific claims. If a scientific claim or its relation to evidence manifests intrinsic epistemic values, then this should serve directly as a reason for the acceptance of the claim (Douglas 2013, 2016), whereas extrinsic ones should have only indirect (Douglas 2013, 2016) effects on what scientific statements are adopted.

Since they are neither indicators of, nor necessary for truth, general moral and social values are widely considered to be non-epistemic or, at best, extrinsic epistemic values. Hence, they can only have an indirect role in the acceptance of scientific statements. ${ }^{2}$

I shall argue for the contrary: Some moral and social values (namely, competence, conscientiousness and honesty) are intrinsic epistemic values that play a genuine epistemic role in the rational acceptance of scientific statements.

\section{Epistemic collaboration and testimony in science}

I proceed from two assumptions. First, epistemic individualism is not viable in science. Epistemic collaboration is necessary for scientists to acquire most scientific truths (e.g., Hardwig 1985, 1991). Second, no scientist on his own could produce all the sufficient epistemic reasons to trust all the persons with whom he is collaborating. Checking the reliability of all his sources, most of whom he does not even know, would require an amount of work that is beyond human capacity (the infeasibility of checking) (e.g., Coady 1992). Consequently, social evidence, like testimony, cannot be reduced to individuals' sources.

In order to locate my antireductionist account of testimony on the map, let us chart the main directions in the epistemology of testimony following Goldman and Blanchard (2018). While reductionism tries to reduce testimonial evidence to another more basic type of evidence, antireductionism takes testimony as an independent source of justification-as a social type of evidence.

Reductionists hold that testimony is not a fundamental source of justification, but it can be reduced to more fundamental ones. According to global reductionists, we can accept testimonies because we have checked earlier ones, found them to be true, and can generalize from these past experiences that testimonies are reliable. Critics

\footnotetext{
2 Notable exceptions are some epistemologists of testimony maintaining that the acceptance of a testimony is partly justified directly by some moral values of the testifier (e.g., Hardwig 1991).
} 
note, as mentioned above, that global reductionism, by denying epistemic dependence, requires unrealistic cognitive capacities and epistemic work from individuals.

Local reductionism reduces the justification of the acceptance of a particular testimony in a given situation to the hearer's evidence concerning the speaker's reliability and other circumstantial factors. For example, Hardwig (1991, p. 699) elaborated a version of this:

(1) $A$ knows that $B$ says that $p$.

(2) $A$ believes (and has good reasons to believe) that $B$ is speaking truthfully, i.e., that $B$ is saying what she believes.

(3) $A$ believes (and has good reasons to believe) that $B$ (unlike $A$ ) is in a position, first, to know what would be good reasons to believe $p$ and, second, to have the needed reasons.

(4) $A$ believes (and has good reasons to believe) that $B$ actually has good reasons for believing $p$ when she thinks she does.

Given (1)-(4), B's testimony gives good reasons for A to believe $p$.

Accordingly, B's trustworthiness is a constitutive element of the reasons justifying A's acceptance of $p$. Hardwig maintained that "the trustworthiness of members of epistemic communities is the ultimate foundation for much of our knowledge." (Hardwig 1991, p. 694) Local reductionism can be generalized over a community in which everyone has a good reason to believe the reliability of others.

However, it is far from obvious that (2)-(4) generally hold in science. Apart from rare occasions, the hearer has no good reasons to believe that the speaker is a reliable and honest knower in the particular situation. Most of the time scientists do not know each other, or if they do, then not well enough to have evidence of the other's reliability and honesty. Without such evidence, the hearer could not accept testimonies. ${ }^{3}$

The relationship between trustworthiness (and other moral and social values) and the epistemic value of testimony cannot be grasped in this way. The problem, I think, lies in the individualistic approach. Generally, a particular hearer cannot have sufficient evidence about the values (e.g., honesty) of a particular speaker, but a community may prescribe certain values and norms that members - speakers and hearers alike - can and should follow.

For the antireductionists, the speaker's testimony that $p$ is a reason for the hearer to accept that $p$ is true unless he has reasons to doubt it. The hearer needs no other reason to accept it than the testimony itself. However, "the negative requirement [lack of any defeater] is extremely weak, many antireductionists add an additional requirement, i.e., that the speaker actually be competent and sincere" (Goldman and Blanchard 2018, p. 7).

It may be true that the negative requirement (the unless-clause above) is extremely weak, yet no additional requirement (like competence and sincerity) of the actual speaker is needed to render antireductionism plausible. As such, I shall show, scientific testimonies, by default, manifest these kinds of values in science.

Reductionism and antireductionism both assume that testimony provides evidence for the truth of what is asserted. Contrary to this, testimony is an assurance according

\footnotetext{
${ }^{3}$ For criticism of local reductionism, see Webb (1993), Govier (1993) and Adler (1994).
} 
to social interactionism. We are justified to accept a testimony (at least, partly) because the speaker takes responsibility for her words (Goldman and Blanchard 2018, pp. 7-8). While the assurance theory (e.g., Moran 2006) locates the role of social and moral values on the speaker's side (in his responsibility), Goldberg (2018) pinned it down to the hearer's legitimate normative expectations. Both kinds of social interactionist views try to capture the epistemic role of moral and social values in the effect they have when manifested by individual agents. Contrary to this second type of individualistic approach, I shall argue again that the epistemic role of social and moral values can be captured in a simpler, though more comprehensive, way on the group level—namely, when we recognize the functions of moral and social values and norms adopted by a scientific community.

Let me generalize this point. Most theories of testimony derive the epistemic quality of testimony primarily from the epistemic and other qualities and states of the speaker and/or the hearer. ${ }^{4}$ Different theories impose different requirements on the speaker and on the hearer as to what epistemic or other qualities and states they should assume in order to make testimony epistemically valuable. Reductionists' theories obviously follow this line. However, antireductionist evidentialism does the same when it wants to include the speaker's reliability, honesty, or the like among the reasons for acceptance. For social interactionists, the qualities and states of the interacting individuals heavily rely on, or are influenced by, social norms. ${ }^{5}$ Nonetheless, it is the qualities and states of the individuals that matter. In sum, all these theories of testimony assume that it is some epistemic, moral, or social quality and state of the individual speaker and/or the hearer on the occasion of testimony that can provide testimony with epistemic value. It seems all natural. Yet, I shall argue that it is the epistemic quality of the social norms of testimony (being epistemically rational) from which the epistemic value of testimony is derived. Competence, honesty, and the like play a role in the justification of the acceptance of testimonies as values and norms of the scientific community-not as personal qualities of individual speakers.

\section{Reduction of the intrinsic epistemic value of testimony}

As a first step in the development of my position, I will show how the intrinsic epistemic value of a testimony (being evidence for what is asserted) can be reduced to the values of its performance (being performed competently, conscientiously, and honestly).

Let us suppose that we are justified to accept the content of a testimony because it is evidence for (a reason to accept) what is asserted.

(i) If a speaker, $s$ asserts that $p$ to a hearer, $h$, then, under normal conditions, it is a reason for $h$ to accept $p$, unless $h$ has special reasons for doubt.

How can a testimony be an epistemically rational reason for the acceptance of its content? A testimony is evidence for what is asserted if and only if (iff) the testimony is an indicator of the truth of its content. Now, a testimony is an indicator of the truth

\footnotetext{
4 Welbourne's $(1979,1981)$ position is a good example for this whereas Lackey's (2006) statement view is a notable exception.

5 See e.g., Goldberg (2018).
} 
of its content iff the testifier is a reliable source of truth in the act he performs. How can a speaker be a reliable source of truth in his communicative action? What are the conditions for this?

$s$ is a reliable source of truth in his testimony regarding $p$ at $t$ iff $s$ competently, conscientiously, and honestly testifies that $p$ at $t$.

Thus,

(ii) a testimony is evidence for its content under normal conditions iff it is a competently, conscientiously, and honestly performed act. ${ }^{6}$

Competence refers to the knowledge, skills, and abilities required to do something well in accordance with applicable standards and norms. The speaker should have all the knowledge, skills, and abilities to testify appropriately according to the standards applicable to the given situation. Testifying competently has epistemic and communicative components. The testifier should have all the competences to produce an epistemically justified statement on the subject matter. She should be able to assess the epistemic reliability of her statement and the requirements of the particular testimonial situation concerning the reliability of the statement. She also should have all the competences to communicate in a way that is adequate to the hearer and the testimonial situation.

Hence, competence includes a variety of capacities in testimony, like cognitive capacities, the capability of correct self-assessment, ${ }^{7}$ linguistic competence, and probably other capacities, as well. Let us understand competence in a broad sense to include every kind of epistemic and communicative competency that is necessary for the biconditional to hold.

Conscientiousness makes sure that the testifier uses her competences carefully and responsibly according to the applicable standards in the particular testimonial act. ${ }^{8}$ Conscientiousness is necessary only in a limited sense for the biconditional to hold. A scientist should act conscientiously in a testimony only as an epistemic and communicative agent, not as a general moral and social agent. A scientist may report that he was successful in manipulating a patient's DNA, which could be an epistemically and communicatively conscientious testimony, yet unethical all things considered.

The speaker testifies honestly when she says, in a straightforward way, what she believes to be appropriate to say under the circumstances. Honesty also involves that she honestly try to follow the norms of testimony that are relevant to the subject matter and to the testimonial situation.

\footnotetext{
6 As mentioned earlier, epistemologies of testimonies usually focus on the speaker's and the hearer's beliefs (states and qualities), and they try to specify the conditions in their terms, under which a testimony is epistemically valuable. My proposal shifts focus in two dimensions: from belief to statement, and from propositions to actions. Biconditional (ii) pertains to how the speaker produces the testimony-how she makes her statement, not what kind of beliefs she has. Lackey $(2006,2011)$ proposed a similar shift form the epistemological properties of beliefs to those of statements. However, she focused on the epistemological properties of the speaker's words, whereas I analyze the speaker's action and the social norms governing it.

7 See Hardwig (1991, p. 700).

8 It is similar to Zagzebski's (2012) notion of conscientiousness.
} 
Note that this notion of honesty is different from many similar concepts that can be found in the testimony literature. Let me mention just a few of them: sincerity (saying without deception what one believes), truthfulness (telling the truth or being disposed to tell the truth), honesty (not trying to deceive). I use the concept of honesty according to the definition above because it is more sensitive to the context of testimonies than the others are.

Testimonial acts and situations may vary in a number of ways. Take the following examples:

(a) the conclusion of a research paper reporting the results of a complex research in a high-profile scientific journal.

(b) the survey of the literature presenting relevant alternative theories in the same paper

(c) an expert opinion of a specialist in a project meeting of a multidisciplinary research team

(d) a reference to an author's position in a workshop discussing a work-in-progress paper (for example, XY says this and that)

They are all testimonies, and their assorted variety has at least three consequences that are relevant to our discussion.

First, different kinds of testimonies support what is testified up to a different extent; therefore, hearers may take them to be reasons for different kinds of acceptance. A hearer may accept the results in (a) as true and build his research project partly on its truth. A reference to an author's position in (d) can be accepted temporarily for the sake of the argument, and its relevance can be studied later.

Second, they may require different kinds of competence and conscientiousness on the part of the speaker. The speaker is supposed to produce a reliable testimony, but in order to do so, she may need different kinds of knowledge and skills. In cases (a) and (c), she should be an expert of the subject matter and believe what she maintains; thus, she is supposed to be a competent knower of her conclusion. Probably she should be a competent researcher on the field, as well. As to (c), the testifier should see at least some of the relevance of her expert advice in the context of the broader research project that she is part of. However, in case (b), she does not have to be an expert of the alternate theories or even know them. Often times, it is enough for her to know that these theories could apply to her research, but for a particular reason, they actually cannot be used. She certainly does not have to believe in those theories (though she may). She could report about them correctly, even if she is skeptical about their truth. ${ }^{9}$ In case (d), she does not have to be an expert on the author or the author's theory or even fully understand the claim she cites; it is enough to know that the citation is correct, and it can be helpful for her colleague at that point of the discussion.

Third, not unrelated from the first, different testimonies may have different consequences if they are false or misleading. So, the acceptance of different testimonies may require different level of soundness and, thus, different level of competence, conscientiousness, and honesty on the speaker's part. ${ }^{10}$ Depending on the subject matter

\footnotetext{
9 Lackey $(2006,2011)$ points out that a speaker may correctly report a true $p$ without believing it.

10 Wilholt (2013) considers the type of testimony in which inductive risk (i.e., the consequences of reporting something that is false or not reporting something though it is true) is an important factor. He suggests specific
} 
and the circumstances, the publication of certain scientific results could have immediate consequences; or sometimes, it can be very difficult or expensive to check their validity. Such testimonies may have to comply with specific additional standards and norms. Contrary to this, there is not usually much at stake when someone makes a statement like (d).

In one direction, the biconditional (ii) says that if a testimony is a competent, conscientious, and honest act, then it is a reason to accept its content. If a testimonial act manifests these values, then the speaker is competent in making a statement that is epistemically sound and appropriately formulated according to the epistemic and communicative standards required by the situation. So much should be sufficient for a hearer to take the testimony as a piece of evidence for its content (provided that she has no reason for doubt).

In the other direction, the biconditional (ii) states necessary conditions. If the speaker does not have the knowledge, skills, or abilities to testify on the subject matter according to the required standards, or if she does not use them carefully in that particular situation, then she can hit the truth only by chance, which is not a reason to accept what she says. Similarly, if she cannot or simply does not communicate adequately in a particular situation, than the hearer cannot take her words seriously. ${ }^{11}$ Finally, if she tries to deceive the receiver or to dodge the required norms and standards, then the receiver obviously cannot take her testimony as a reason to believe her. Thus, it seems that the competence, conscientiousness, and honesty in the performance of a testimonial act are also necessary for this linguistic act to provide evidence for its content. In addition, our practice also bears this out. If you learn that a statement was made incompetently, unconscientiously, or dishonestly, then it would be a reason for you not to take testimony as evidence for what was said. It would ruin the evidential status of the testimony.

According to (ii), a testimony embodies an intrinsic epistemic value, that is, it is evidence, iff it embodies an extrinsic epistemic value (competence) and general moral and social values (conscientiousness and honesty). The intrinsic epistemic value of evidence is equivalent to the combined value of competence, conscientiousness, and honesty with respect to testimony. The extension of the " $x$ is evidence" predicate and the extension of " $x$ is a competently and conscientiously and honestly performed act" predicate are coextensive in the set of testimonies.

The claim (ii) states the equivalence of values, but it also involves the reduction of the intrinsic epistemic value of a testimony. Eventually, the competent, conscientious, and honest performance of testimony makes the testimony epistemically intrinsically valuable. In other words, the intrinsic epistemic value of a testimony is grounded in the values manifested by its performance. The intrinsic epistemic value of evidence is reduced to the value of the competent, conscientious, and honest performance in the domain of testimonies. By reduction of a value to other values, I mean that the former

\footnotetext{
Footnote 10 continued

norms of competence (e.g., assess the inductive risk) and specific norms of conscientiousness (e.g., consider the possible effects regarding the research projects of fellow scientists).

11 For example, imagine the following conversation. You are obviously in great trouble and ask someone coming by: "Excuse me. Is this the way to the emergency room?" He answers carelessly and somewhat nervously without looking up from his phone: "Yeah." His testimony may not be taken earnestly in the situation, even if it is epistemically sound.
} 
is extensionally identical to the latter (that is, the set of testimonies manifesting the former is identical with the set manifesting the latter), and the manifestation of the former value is grounded on or derived from the manifestation of the latter values.

Since the competent, conscientious, and honest performance of a testimony is indicative of the truth of its content, therefore, the combination of the three is an intrinsic epistemic value of testimonies.

According to the generally accepted view, however, competence, conscientiousness, and honesty would fall-at best-in the category of extrinsic epistemic values in science, promoting the attainment of truth but neither indicating it nor being necessary for it. Now it turns out that they are intrinsic epistemic values indicating the truth of scientific statements asserted in testimonies. Consequently, they are intrinsic epistemic values in science. ${ }^{12}$

\section{Justification of the acceptance of testimony}

By value reduction, we can ground the rationality of the default acceptance of testimony on the established norms of testimony in the scientific community.

Values govern acts, inter alia, by norms ensuing from them and promoting their manifestation. The values of competence, conscientiousness, and honesty entail the following norms:

- Testify competently.

- Be conscientious and honest when you testify.

Regarding testimonies, the values and norms of competence, conscientiousness, and honesty are instilled into scientists and constantly enforced by scientific practices. $\mathrm{PhD}$ supervisors and reviewers teach the candidate how to report on her and others' research, and they constantly check whether the candidate is observing the pertaining norms in her thesis and publications. It is an important part of a Ph.D. program to train the students how to write papers and a thesis - that is, how to testify in a written form. Students' competencies in the subject matter, in doing original research and reporting on it, are developed hand in hand in Ph.D. training. In this process, she is also taught the standards of different kinds of testimonies. She is taught about the exemplars to follow and the sort of accuracy to maintain when citing someone else's work, describing the experiment she conducted, presenting the critical evaluation of her results, acknowledging other's help, and so on. Her supervisor and senior colleagues on her research team are her role models, exhibiting the level of competence, conscientiousness, and honesty she is expected to adopt in the different forms of testimonies. She is also given negative feedback immediately if her comments do not represent the expected competencies or meet the required standards, if she did not draft a paper conscientiously, or if she did not internalize the norms of scientific

\footnotetext{
12 Steel (2010) maintains that epistemic values are context-dependent. An extrinsic value combined with other (probably intrinsic) values can become an intrinsic epistemic value in the context of those epistemic values. Steel (2010, p. 19) mentions that testability is an extrinsic epistemic value on its own. However, testability becomes an intrinsic epistemic value when it is combined with empirical accuracy (which, in turn, is an intrinsic epistemic value in itself).
} 
communication well enough. Similar ways of teaching and enforcing the norms of testimony are present in the meetings of research teams, review processes of scientific publications and conference abstracts, discussions of conference presentations and print publications, and (rare) ethical debates.

If members of a scientific community follow and enforce the norms of testimony ensuing from its values, then - because of value reduction - it is epistemically rational for the community to take testimonies as evidence and to uphold and enforce the norm of the acceptance of testimonies:

- Take a testimony as a reason for the acceptance of its content unless you have reasons for doubt. ${ }^{13}$

The epistemic rationality of the norm of acceptance can be explained in the following way. If a community upholds and strictly enforces the norms of testimony, then it is a reason to suppose that members follow these norms. Furthermore, if members observe the norms of testimony, then, because of value reduction, they produce epistemically valuable testimonies that serve as evidence for their content. Therefore, it is a justified default assumption that scientific testimonies follow the norms and manifest the values that are explicitly upheld and enforced by the community.

The norm of acceptance is based on the assumption that scientists follow the norms of testimony and produce epistemically valuable testimonies. Insofar as testimonies manifest their intrinsic epistemic value (being evidence for their content), then the norm of acceptance guarantees that the members of the scientific community accept statements on the basis of appropriate reasons. The norm of acceptance is an epistemically rational norm in this sense. ${ }^{14}$

When a hearer accepts the content of a testimony merely by following the norm of acceptance then he accepts it by virtue of the appropriate reason. Consequently, the hearer is epistemically rational to accept what the speaker says merely by following the norm of acceptance. Thus, when a hearer complies with the norm of acceptance, he then adopts rational means to acquire justified statements.

The norms of competence, conscientiousness, and honesty are to promote the truth of testimonies, while the norm of acceptance is to promote the dissemination of testimonial truths.

The norm of acceptance is reflected in the citation practice of scientists. A scientist is supposed to cite and rely on the most recent results of others in the field. When he refers to the results of his fellow scientists, he can and should accept them, and he needs good reasons to challenge them. Scientists are trained to adopt the values and

\footnotetext{
13 Of course, this norm is not applicable when the hearer is given two testimonies contradicting each other because the contradiction gives him a profound reason to doubt one of the statements. For instance, Goldman (2001) discusses the kinds of empirical evidence that a hearer who is not an expert in the field might have or be able to obtain for accepting one expert's scientific testimony rather than her rival's. The sources of evidence that the hearer can fall back on might have normative bearings (like the credentials of the speakers); nevertheless, they provide the hearer individual empirical justification for his decision.

14 It is always a matter of degree of how successfully a community can enforce its norms. Accordingly, the norm of acceptance can be more-or-less rational epistemically.
} 
norms concerning testimony. They are admitted to the scientific community only if they follow the norms and if they suppose that others also follow them. ${ }^{15}$

Of course, values and norms are sometimes neglected or overridden. Therefore, caution is in place to be alert to reasons for doubt as the "unless" clause indicates. Being fallible, the speaker can be wrong even if she does her best to follow the norms of testimony.

On my interpretation, a hearer follows an epistemically rational norm, giving him a reason to accept what is asserted in a testimony. The justification behind this simple rule following can be spelled out in the following way.

1. If a speaker testifies competently, conscientiously, and honestly, then the testimony is a reason to accept what is asserted.

2. Competence, conscientiousness, and honesty are strict norms of testimony in science.

3. If these are strict norms in science, then this is a reason to suppose that members of the scientific community follow them.

4. If members follow them, then they produce testimonies that are reasons for the acceptance of their content.

- Therefore, the norm of the acceptance of testimony is epistemically rational in science.

5. The hearer is given a testimony.

6. The hearer has a good reason to believe that the speaker belongs to the scientific community, ${ }^{16}$ and it is a scientific testimony.

- Therefore, the hearer is expected and justified to follow the norm of the acceptance of testimony.

- Therefore, the hearer can and should take the speaker's testimony as a reason to accept what is asserted (unless he has reason for doubt).

- Therefore, the hearer can accept rationally — on the ground given him in the previous step-what is asserted (unless he has reason for doubt). ${ }^{17}$

We should distinguish the actual process of acceptance and the process of justification explicated in this inference (Audi 1997). This argument shows why the hearer is justified to follow the norm of acceptance and, eventually, accept what is asserted.

\footnotetext{
15 Reid (1983, pp. 94-94) assumed that God implanted two principles in human beings. "The first of these principles is, a propensity to speak truth, and to use the signs of language, so as to convey our real sentiments." "Another original principle implanted in us by the Supreme Being, is a disposition to confide in the veracity of others, and to believe what they tell us. This is the counter part to the former; and as that may be called the principle of veracity, we shall, for want of a more proper name, call this the principle of credulity." It is very likely that they are, indeed, implanted in us though not by God but by our social group-by the scientific community, in our case.

16 The hearer may assume that the speaker belongs to the scientific community if she is trained and accepted by the community. In such cases, she is trained to follow the norms and has proved herself consistent to follow them. Note the general reservation toward outsiders. If a speaker is not trained in a special field, then she has to prove herself harder, and she, along with many of her testimonies, have to overcome more doubts to get adopted than someone with proper training.

17 According to this account, testimony is not a transmission of the speaker's belief/epistemic properties to the hearer. It is not the speaker's knowledge or some epistemic properties of her beliefs that justifies the hearer to adopt the speaker's belief that was communicated. (See Lackey's 2006, 2011). However, transmission view constitutes the mainstream and non-transmission view is the minority.
} 
However, the hearer most likely accepts a testimonial claim automatically, just following the norm of acceptance without knowing the argument above, or without thinking it over.

Let us contrast my group-level account with a similar individualist one to highlight the differences. An individualist account would use the hearer's beliefs in a justifying inference like this (or a similar one):

A. The hearer believes that if a testimony is competent, conscientious, and honest, then the testimony is a reason to accept what is asserted.

B. The hearer believes that competence, conscientiousness, and honesty, are strict norms in science.

C. The hearer believes that if they are strict norms in science, then this is a reason to assume that members of a community follow them.

D. The hearer is given a testimony.

E. The hearer has a good reason to believe that the speaker belongs to the scientific community, and that this is a scientific testimony.

- Therefore, the hearer has a reason to believe that the speaker follows the norms (competence, conscientiousness, honesty).

- Therefore, the hearer has a reason to follow the norm of acceptance of testimony.

- Therefore, the hearer takes the testimony as a reason to accept what is said (unless she has reason for doubt).

- Therefore, the hearer can accept rationally — on the ground she rationally accepted in the previous step-what is asserted (unless she has reason for doubt).

An argument like this would give the hearer reasons to believe in the content of a testimony in terms of his beliefs. On this account, it would be the hearer's background knowledge about the values and norms of scientific testimonies, in general, and his knowledge about the particular testimony and his inferential rationality that establishes his belief in the content of testimony. This is not what I suggest. I do not think it is plausible to assume that the hearer-apart from rare occasions-has a comprehensive overview of the operation of values and norms of scientific testimony; consequently, premises (A)-(C) are false, and the argument cannot be sound.

The rationality of the acceptance of a testimony does not spring from the hearer's beliefs about the reliability of the testifier and/or the rationality of the testimonial norms. The hearer can rationally believe in the testimony not because he has additional evidence about the trustworthiness of the speaker, the trustworthiness of the community, or the rationality of the testimonial norms he is supposed to follow. As mentioned earlier, a receiver of a testimony usually cannot have evidence of the competence, conscientiousness, and honesty of her fellow scientists. Individual character traits of the testifiers or the properties of particular testimonies do not matter in the evidential value of testimonies because the hearer generally has no reason to believe in them. Similarly, he probably does not have evidence to believe that the norms of testimony are rational and enforced in several ways. However, he can and does know how to follow the norms of the scientific community. The norm-based assumption that 
the speaker produces epistemically valuable testimony, and the rationality of the norm of acceptance justify the hearer's acceptance of what is asserted. ${ }^{18}$

Note the similarity with the Gricean maxims. The Gricean maxims establish efficient communication not because speakers believe that these norms are useful, as most speakers know nothing about them, but rather because they are rational means to that end and people follow them. Likewise, the fact that the scientific values and norms concerning testimony are rational means for scientists to produce and accept justified statements, and that people can be supposed to follow them, justify the hearer to accept the content of a testimony-not his beliefs about these facts. Speakers and hearers just blindly follow the rules in the Gricean cases, and, yet, they behave (means-end) rationally to communicate efficiently. Likewise, even if scientists just blindly follow the rules of testimony, their behavior is epistemically rational. ${ }^{19}$

Of course, scientists are often critical toward testimonies (and their content) and have several methods to probe the reliability of testifiers and the act and content of testimonies. However, most of the time, they follow the norm of acceptance automatically and blindly. Be it as it may, given that a complete check is infeasible and epistemic dependence is unavoidable, there remains some blindness anyway. The good news is that even if scientists blindly follow the rules, they can be rational. The norm of acceptance is an epistemically rational rule, and it prescribes an epistemically rational behavior. Therefore, it is epistemically rational for a scientist to take testimony as evidence (under normal circumstances) according to the norm of acceptance. In the end, even if scientists blindly follow the rule of acceptance, they accept what is asserted in an epistemically rational way.

The epistemic rationality of the norm of acceptance makes the non-reductive evidentialist position epistemically stronger. Antireductionists claim that the speaker's testimony of $p$ is a reason for the hearer to accept $p$ unless he has reasons to doubt it. As mentioned earlier, many criticized this entitlement, saying that it is epistemologically weak because it rests only on the lack of counterevidence. However, the epistemic rationality of the norm of acceptance gives a much stronger epistemic ground for the hearer to accept $p$ than the lack of reason for doubt.

\section{Concluding remarks}

Moral and social values play an essential role in science, even if science is viewed as an epistemic enterprise. By value reduction, the intrinsic epistemic value of testimony translates into moral and social values. If a testimony realizes its moral and social values, then it also manifests evidence for what is said. The moral and social norms of testimony (competence, conscientiousness, and honesty) operationalize the way in which a scientist can give reason to the members of the scientific community to accept propositions that would be out of their reach otherwise. Many of our scientific statements are grounded in moral and social norms. The rationality of these norms make

18 Goldman (2011) distinguished different levels of social epistemology such as group-level social epistemology and the social epistemology of individual scientists. The epistemology of testimony I suggest, belongs to group-level social epistemology, not the social epistemology of individual scientists.

19 This is kind of an answer to Hardwig's question: "How can knowledge be blind?"(Hardwig 1991, p. 693). 
second-hand scientific beliefs rational for those who have no first-hand justifications, being epistemically dependent on others.

However, this conclusion does not ground the rationality and the truths of science on the quicksand of (the data about) the contingent moral and social character of individual scientists. Instead, the rationality and the truths of science are, in part, based on epistemically rational, moral, and social values and norms of the scientific community. Moral and social values and norms are no less firm and reliable than, say, the values and norms of observation or inference that should, at least partly, also ground the empirical rationality of science.

It should be noticed that the values and norms involved in scientific testimony and their role of its acceptance can be generalized to other testimonial situations. For example, one might argue that testimonies work in the same way in certain legal systems. Legal systems also involve robust and rational norms of testimony that can epistemically justify their acceptance. Similarly, corporate cultures usually place great value on competence, conscientiousness, and honesty, and people in teams are justified to accept the testimony of other team members for the same reasons as scientists.

However, no robust group values or norms support other kinds of testimonies. If you ask a stranger to give you directions, then the norms of her testimony are epistemically weaker than the norms of testimony in science, and they are enforced in different ways and followed to different extent. These general values and norms give only weaker reason for us to take testimony as evidence, than in science, thus triggering more vigilance to doubt.

I suggest that we should introduce order to the diversity of testimonies by segmenting epistemic groups, ${ }^{20}$ as different groups uphold, pursue, and enforce competence, conscientiousness, and honesty in testimony to a different extent. Consequently, members of different groups may have more or less reasons to accept testimonies by default and, thus, less or more ground to look for reasons for doubt.

Acknowledgements Open access funding provided by Eötvös Loránd University. I am greatly indebted to Ákos Gyarmathy for his constant encouragement and for the useful discussions we had on these topics. My sincere thanks also go to two reviewers for their valuable and meticulous comments that improved this paper a lot.

Open Access This article is licensed under a Creative Commons Attribution 4.0 International License, which permits use, sharing, adaptation, distribution and reproduction in any medium or format, as long as you give appropriate credit to the original author(s) and the source, provide a link to the Creative Commons licence, and indicate if changes were made. The images or other third party material in this article are included in the article's Creative Commons licence, unless indicated otherwise in a credit line to the material. If material is not included in the article's Creative Commons licence and your intended use is not permitted by statutory regulation or exceeds the permitted use, you will need to obtain permission directly from the copyright holder. To view a copy of this licence, visit http://creativecommons.org/licenses/by/4.0/.

\section{References}

Adler, J. (1994). Testimony, trust, knowing. The Journal of Philosophy, 91, 264-275.

\footnotetext{
20 Kusch (2002, p. 53) justly criticized the vagueness of the concept of epistemic/knowledge communities (Hardwig 1985/Welbourne 1981). Here, groups are defined by their shared values and norms, and not by their distributed/shared knowledge.
} 
Audi, R. (1997). The place of testimony in the fabric of knowledge and justification. American Philosophical Quarterly, 34, 405-422.

Coady, C. A. J. (1992). Testimony: A philosophical study. Oxford: Oxford University Press.

Douglas, H. (2009). Science, policy, and the value-free ideal. Pittsburgh, PA: University of Pittsburgh Press.

Douglas, H. (2013). The value of cognitive values. Philosophy of Science, 80(5), 796-806.

Douglas, H. (2016). Values in science. In P. Humphreys (Ed.), The Oxford handbook of philosophy of science (pp. 609-631). Oxford: Oxford University Press.

Goldberg, S. (2018). What we owe each other, epistemologically speaking: Ethico-political values in social epistemology. Synthese. https://doi.org/10.1007/s11229-018-01928-6.

Goldman, A. I. (2001). Experts: Which ones should you trust? Philosophy and Phenomenological Research, 63(1), 85-110.

Goldman, A. I. (2011). A guide to social epistemology. Goldman and Whitcomb, 2011, 11-37.

Goldman, A., \& Blanchard, T. (2018). Social epistemology. In E. N. Zalta (Ed.), The Stanford encyclopedia of philosophy (Summer 2018 Edition). https://plato.stanford.edu/archives/sum2018/entries/ epistemology-social/.

Govier, T. (1993). Trust and testimony: Nine arguments on testimonial knowledge. International Journal of Moral and Social Studies, 8, 21-39.

Hardwig, J. (1985). Epistemic dependence. The Journal of Philosophy, 82, 335-349.

Hardwig, J. (1991). The role of trust in knowledge. The Journal of Philosophy, 88, 693-708.

Kusch, M. (2002). Knowledge by agreement: The programme of communitarian epistemology. Oxford: Oxford University Press.

Lackey, J. (2006). Learning from words. Philosophy and Phenomenological Research, 73(1), 77-101.

Lackey, J. (2011). Testimony: Acquiring knowledge from others. Goldman and Whitcomb, 2011, 71-91.

Lackey, J., \& Sosa, E. (Eds.). (2006). The epistemology of testimony. Oxford: Oxford University Press.

Moran, R. (2006). Getting told and being believed. Lackey and Sosa, 2006, 272-306.

Reid, T. (1983). Inquiry and essays. In Beanblossom, R., \& Lehrer, K. (Eds.), Indianapolis: Hackett.

Rolin, K. (2015). Values in science: The case of scientific collaboration. Philosophy of Science, 82(2), $157-177$.

Steel, D. (2010). Epistemic values and the argument from inductive risk. Philosophy of Science, 77(1), $14-34$.

Webb, M. O. (1993). Why I know about as much as you: A reply to Hardwig. The Journal of Philosophy, 90, 260-270.

Welbourne, M. (1979). The transmission of knowledge. Philosophical Quarterly, 29, 1-9.

Welbourne, M. (1981). The community of knowledge. The Philosophical Quarterly, 31, 302-314.

Wilholt, T. (2013). Epistemic trust in science. The British Journal for the Philosophy of Science, 64(2), 233-253.

Zagzebski, L. (2012). Epistemic authority: A theory of trust, authority, and autonomy in belief. New York, NY: Oxford University Press.

Publisher's Note Springer Nature remains neutral with regard to jurisdictional claims in published maps and institutional affiliations. 